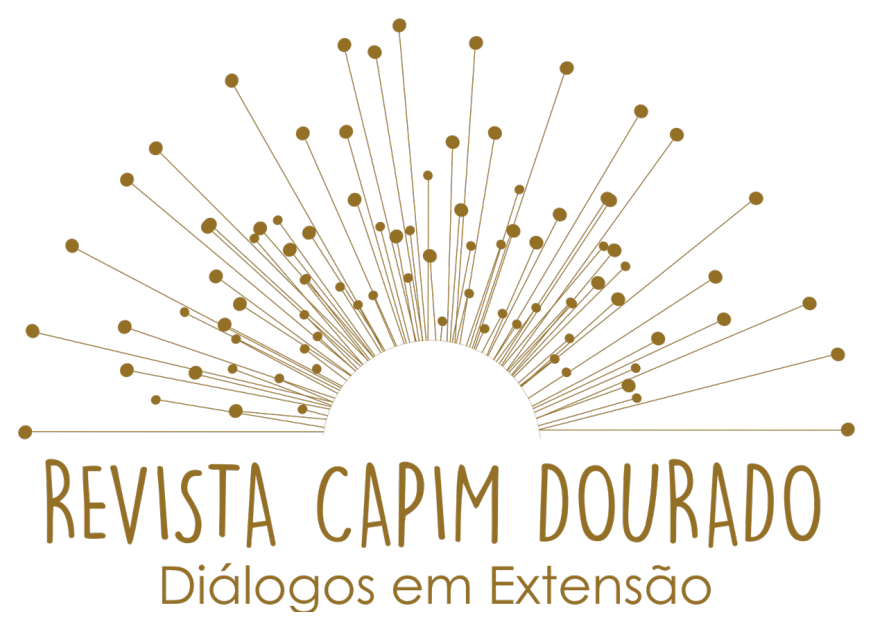

ISSN n² 2595-7341

Vol. 3, n. 2, Maio-Agosto, 2020

DOI: http://dx.doi.org/10.20873/uft.2595-7341.2020v3n2p70

\title{
CURSO COVID-19 E O PROCESSO DE TRABALHO NA ATENÇÃO PRIMÁRIA À SAÚDE: territórios, atores e diálogos
}

COVID-19 AND THE PRIMARY HEALTH CARE WORK PROCESS COURSE: territories, actors and dialogues course

CURSO COVID-19 Y EL PROCESO DE TRABAJO EN ATENCIÓN PRIMARIA DE SALUD: territorios, actores y diálogos

\author{
Rui Massato Harayama ${ }^{1}$ \\ Juliana Gagno Lima² \\ Edenira Nunes Costa ${ }^{3}$ \\ Julien Thalita Rocha dos Santos ${ }^{4}$
}

\section{RESUMO}

Experiência de curso ministrado na modalidade de Ensino a Distância sobre a Covid19 destinado a profissionais de saúde e lideranças comunitárias atendidos pela $9^{\circ}$ Região de Saúde do Estado do Pará com ênfase da Atenção Primária à Saúde no

\footnotetext{
${ }^{1}$ Docente do curso de Licenciatura em ao em antropologia da Universidade Federal do Oeste do Pará (UFOPA) no Instituto de Saúde Coletiva.), Pará, rui.harayama@gmail.com.

2 Docente do curso de Licenciatura em Nutrição da no Instituto de Saúde Coletiva (ISCO) na Universidade Federal do Oeste do Pará (UFOPA), Pará, julianagagno@gmail.com.

3 Discente do curso de Saúde Coletiva em Universidade Federal do Oeste do Pará, UFOPA, Brasil, edeniranunes@gmail.com.

${ }^{4}$ Discente do curso de Licenciatura em interdisciplinar em saúde Universidade Federal do Oeste do Pará, UFOPA, Brasil, Pará, julientrs@gmail.com.
} 


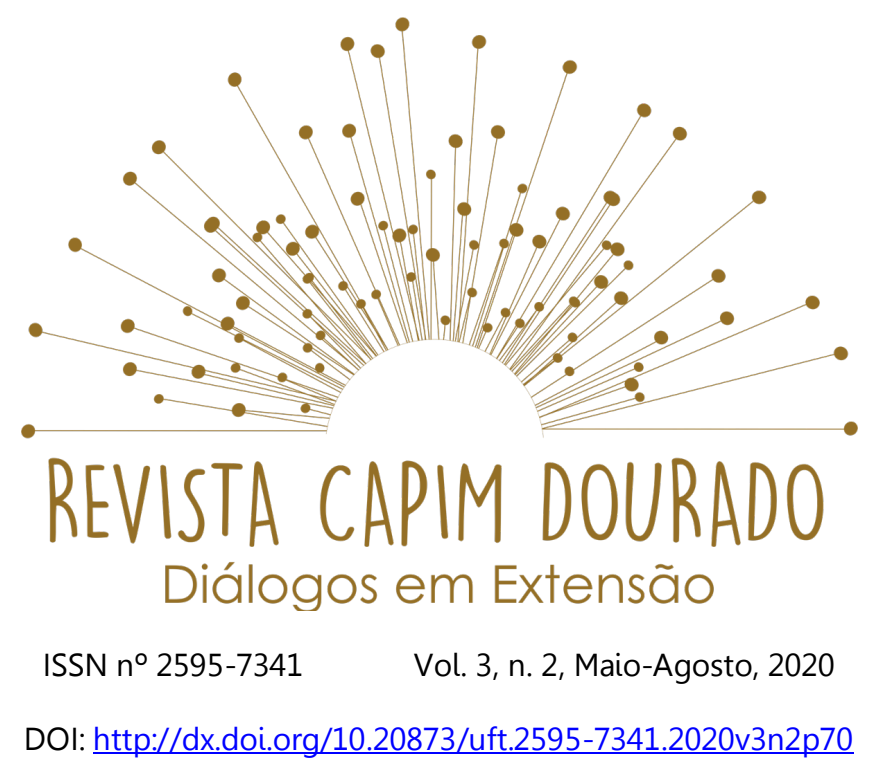

enfrentamento da pandemia. O curso foi realizado durante os meses de Abril e Maio de 2020.

PALAVRAS-CHAVE: Educação Continuada; Amazônia, Infecções por Coronavírus

\begin{abstract}
Experience of a web-based distance learning course on Covid-19 for health professionals and community leaders assisted by 9th Health Region of Para's State with emphasis on Primary Health Care during the pandemic. The course was held during the months of April and May 2020.
\end{abstract}

KEWYWORDS: Continuing Education; Amazon; Coronavirus Infections

\title{
RESUMEN
}

Experiencia de un curso impartido en la modalidad de Educación a Distancia en Covid-19 para profesionales de la salud y líderes comunitarios atendidos por la Novena Región de Salud del Estado de Pará con énfasis en Atención Primaria de Salud para enfrentar la pandemia. El curso se realizó durante los meses de abril y mayo de 2020.

PALABRAS CLAVE: Educación Continua; Amazonas, infecciones por coronavirus.

Recebido em: 31.03.2020. Aceito em: 19.04.2020. Publicado em: 30.05.2020. 


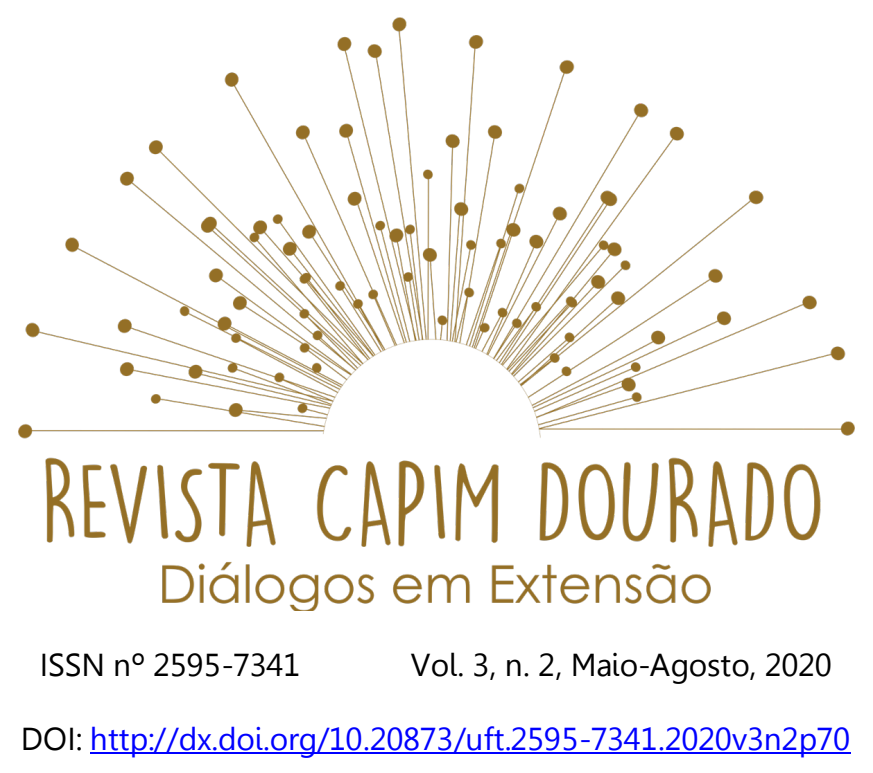

Na região amazônica, os desafios na implantação de políticas públicas de saúde se intensificam em relação às demais regiões brasileiras, devido desigualdades de acesso e grande diversidade geográfica, populacional, social e cultural, com implicações diferenciadas para a organização do sistema de saúde (Confalonieri, 2005).

A região Oeste do Pará, recorte Amazônico nesse relato, abrange 20 municípios das regiões de saúde do Baixo Amazonas e Tapajós. Concentra uma população de 927.553 pessoas, $12 \%$ da população do Estado do Pará e 41\% (519.877,00 km2) da área total do Estado, apresentando baixa densidade demográfica. Apesar de um avanço desde os anos 2000, o IDH da maior parte dos municípios é classificado como baixo.

\section{Descrição do curso}

O curso surge a partir da necessidade de qualificar as ações da APS durante a pandemia e foram planejadas a partir do diagnóstico realizado em Março pela equipe: (1) solicitação dos Agentes Comunitários de Saúde (ACS) por qualificações em formato ativo e criativo; (2) suspensão dos encontros de educação permanente nas unidade básicas de saúde; (3) ausência de materiais do Ministério da Saúde e da Fiocruz voltados para a APS, e (4) fenômeno da infodemia gerando dificuldade na comunicação em saúde. 


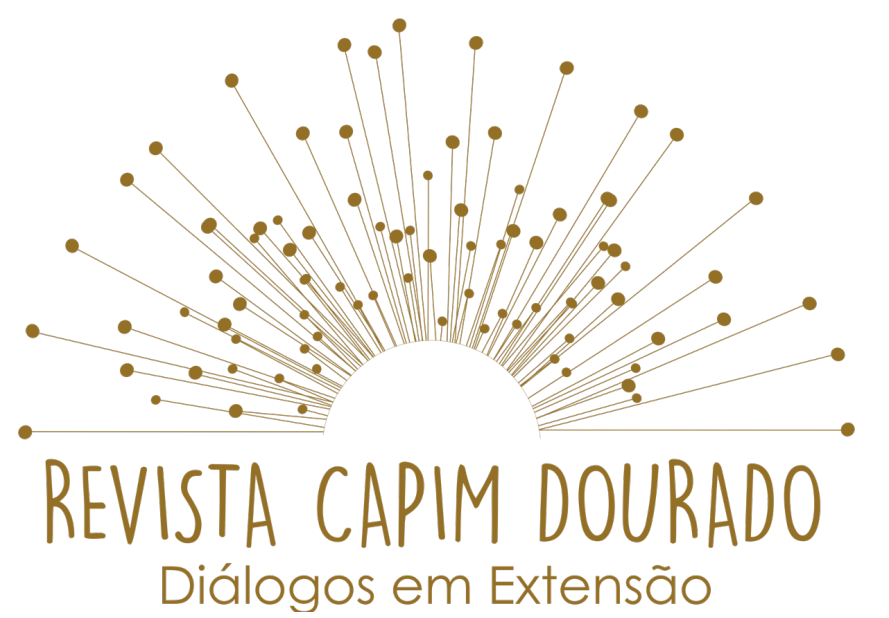

ISSN n 2595-7341 Vol. 3, n. 2, Maio-Agosto, 2020

DOI: http://dx.doi.org/10.20873/uft.2595-7341.2020v3n2p70

Em abril, foram realizadas reuniões com as instituições de ensino superior em saúde da região, o Centro Regional de Saúde e representantes da APS dos municípios do entorno. E validou-se a estrutura do curso com foco no cuidado integral e humanizado, preconizando a precaução de contato e à orientação correta no modo de prevenção e cuidado ao usuário.

Os atores envolvidos na execução foram: coordenação, tutores (alunos egressos) e apoio (representantes das instituições parceiras).

O curso foi organizado em 5 módulos, no Google Classroom, e uma atividade de intervenção. Todos os módulos foram subsidiados por materiais instrucionais sobre o tema (textos, vídeos, materiais em formato pdf) e continham atividade de avaliação, no formato de fórum para interação entre os cursistas.

\begin{tabular}{ll}
\hline Módulo & Objetivo \\
\hline $\mathbf{1}$ & Sintetizar conhecimentos básicos referentes à Covid-19 \\
\hline $\mathbf{2}$ & $\begin{array}{l}\text { Discutir o papel da APS e a reorganização do processo de trabalho na } \\
\text { coordenação do enfrentamento da doença }\end{array}$ \\
\hline $\mathbf{3}$ & $\begin{array}{l}\text { Promover reflexão sobre as orientaçães específicas aos profissionais dos } \\
\text { serviços essenciais }\end{array}$ \\
\hline $\mathbf{4}$ & Promover a intersetorialidade com diferentes atores do território \\
\hline $\mathbf{5}$ & Planejar atividade de intervenção no território \\
\hline & Tabela 1. Organização dos módulos do Curso
\end{tabular}




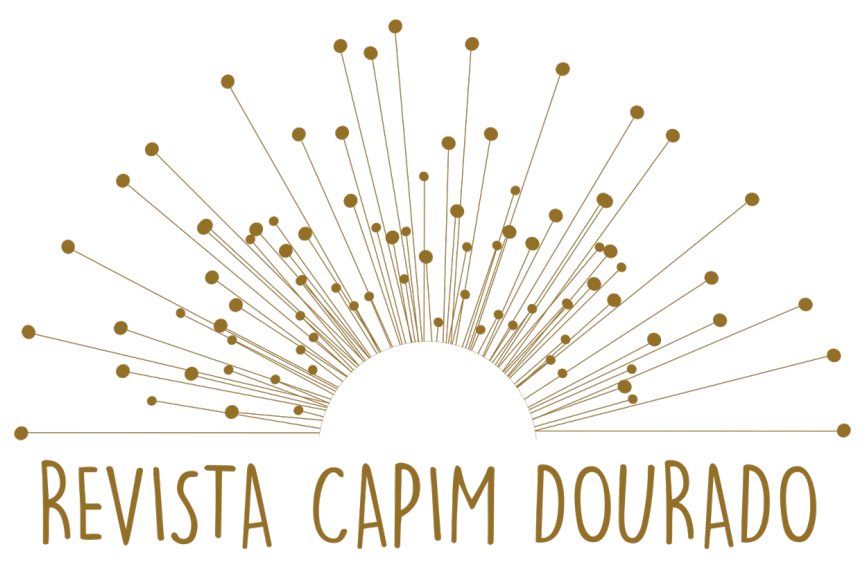

\section{Diálogos em Extensão}

ISSN n 2595-7341 Vol. 3, n. 2, Maio-Agosto, 2020

DOI: http://dx.doi.org/10.20873/uft.2595-7341.2020v3n2p70

A formulação do curso teve as seguintes perguntas norteadoras: no período de enfrentamento da COVID-19, como as equipes de APS podem se manter protagonistas nos cuidados em saúde e ao mesmo tempo, com seus profissionais protegidos? Como a APS pode fortalecer sua atuação no território, de forma a reduzir riscos de contaminação da população e mobilizar estratégias de enfrentamento locais?

\section{Resultados}

A divulgação do curso foi feita por meio de redes de contatos, lista de e-mails e uso da mídia local. (Figura 1)

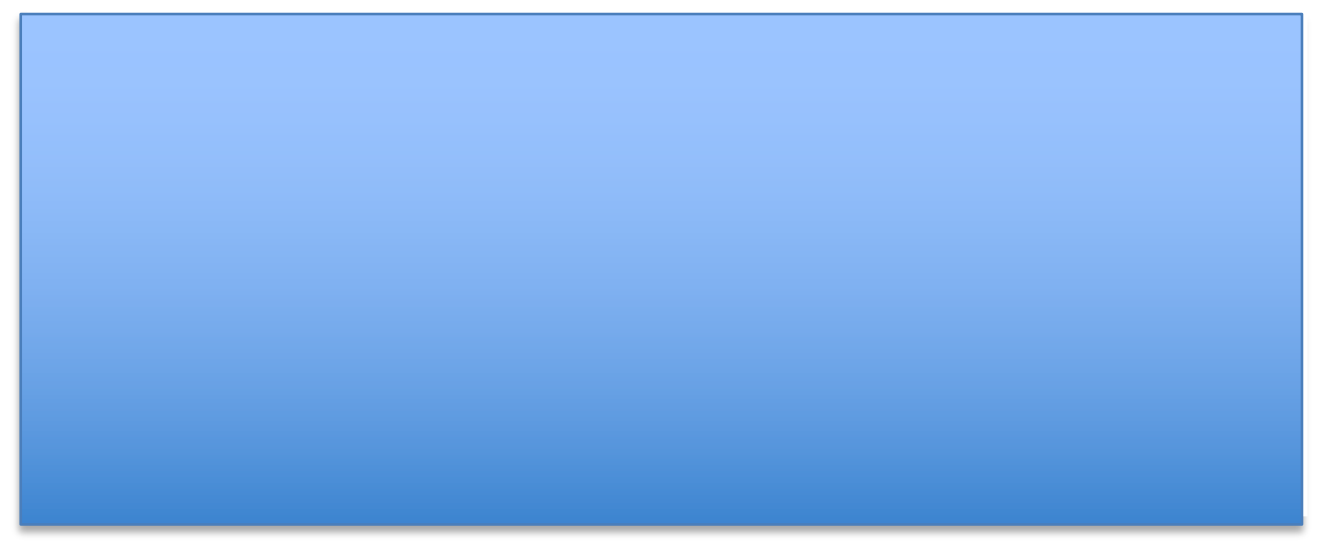
anonimato

Figura 1. Cartaz de divulgação do curso - retirado para garantia do 


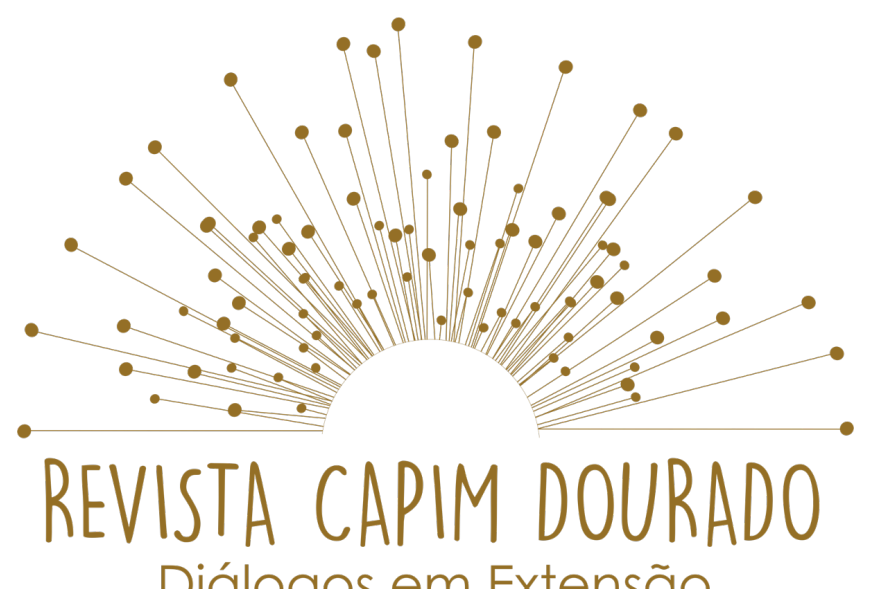

\section{Diálogos em Extensão}

ISSN no 2595-7341 Vol. 3, n. 2, Maio-Agosto, 2020

DOI: http://dx.doi.org/10.20873/uft.2595-7341.2020v3n2p70

O curso recebeu 518 inscrições de 19 municípios, sendo 68\% da cidade de Santarém, 180 profissionais da enfermagem, sendo 60,4\% profissionais da enfermagem e de ACS. Além dos profissionais da saúde também foram recebidas inscrições de trabalhadores de comércios e serviços essenciais (11) e lideranças comunitárias (5). Para atender a demanda foram criadas 8 turmas, com cerca de 50 a 90 alunos cada, organizados por proximidade geográfica. A primeira turma foi iniciada no dia 17 de abril e a última turma finalizada em 31 de maio. Das 518 inscrições, tivemos 201 alunos ativos (com pelo menos 1 acesso), média de 25 alunos por turma e 47 concluintes, os quais realizaram todas as atividades dos módulos e fizeram a proposta de intervenção no território.

\begin{tabular}{lcc}
\hline Município & $\mathbf{N}^{*}$ & $\%$ \\
\hline Santarém & 352 & 68,0 \\
Oriximiná & 39 & 7,5 \\
Monte Alegre & 22 & 4,2 \\
Óbidos & 18 & 3,5 \\
Itaituba & 14 & 2,7 \\
Juruti & 10 & 1,9 \\
Alenquer & 8 & 1,5 \\
Rurópolis & 8 & 1,5 \\
Terra Santa & 8 & 1,5 \\
Prainha & 7 & 1,4 \\
\hline
\end{tabular}




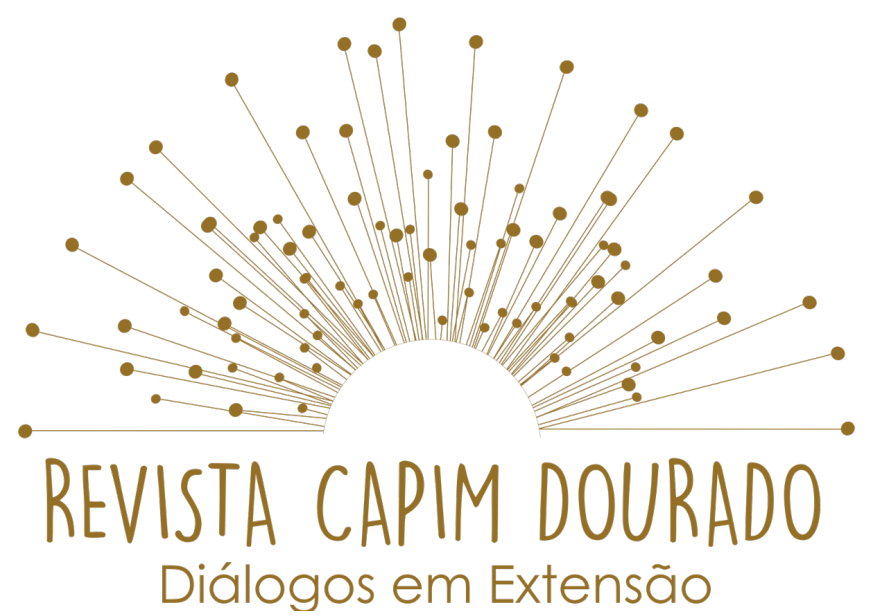

ISSN n 2595-7341 Vol. 3, n. 2, Maio-Agosto, 2020

DOI: http://dx.doi.org/10.20873/uft.2595-7341.2020v3n2p70

\begin{tabular}{lcc}
\hline Mojuí dos Campos & 6 & 1,2 \\
Placas & 6 & 1,2 \\
Belterra & 5 & 1,0 \\
Faro & 5 & 1,0 \\
Almerim & 4 & 0,8 \\
Curuá & 3 & 0,6 \\
Jacareacanga & 1 & 0,2 \\
Novo Progresso & 1 & 0,2 \\
Trairão & 1 & 0,2 \\
Total & 518 & 100,0
\end{tabular}

Tabela 1 Inscritos por município, Curso COVID-19 e APS, Região Oeste do Pará, 2020. Elaboração própria.

As avaliações revelaram que o curso oportunizou a sistematização dos conhecimentos referentes à Covid-19 por meio de dados seguros e informativos; e contribuiu para desenvolver a autonomia dos cursistas.

De parte da equipe de coordenadores e tutores, verificou-se que ministrar um curso EAD demanda esforço coletivo e contínuo, desenvolvimento de estratégias para motivar diariamente os cursistas, visando assim uma maior troca de informações e conhecimentos, além de oportunizar uma constante atualização. 


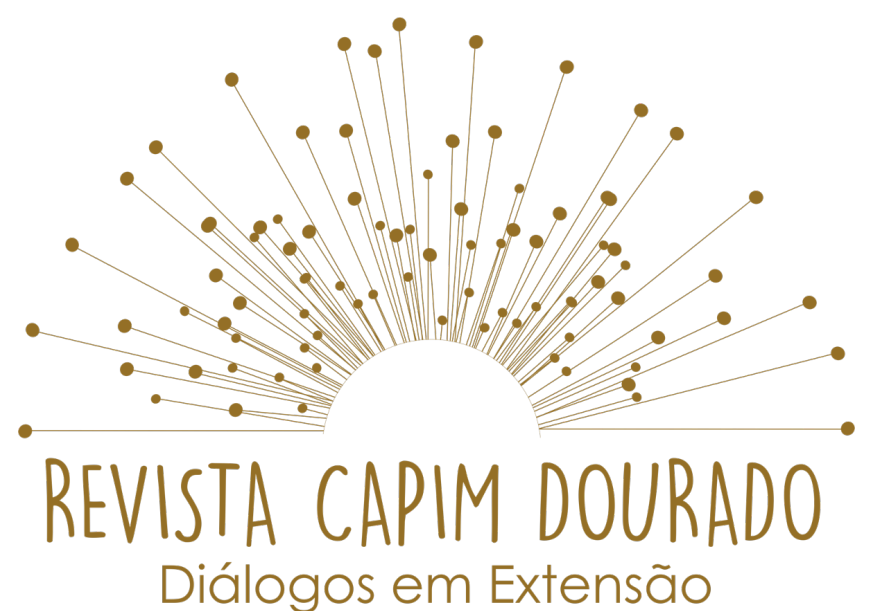

ISSN n 2595-7341 Vol. 3, n. 2, Maio-Agosto, 2020

DOI: http://dx.doi.org/10.20873/uft.2595-7341.2020v3n2p70

A partir do Quadro 1, percebe-se a variedade de temáticas propostas pelos cursistas, extrapolando sua área direta de intervenção, com propostas de ações intersetoriais e multidisciplinares.

\begin{tabular}{|c|c|c|c|}
\hline Município & Profissão & Título da intervenção & Descrição \\
\hline Santarém & $\begin{array}{l}\text { Trabalhador } \\
\text { comércio ou } \\
\text { serviços } \\
\text { essenciais }\end{array}$ & $\begin{array}{l}\text { Orientando clientes de } \\
\text { uma drogaria } \\
\text { santarena a respeito } \\
\text { do Coronavírus }\end{array}$ & $\begin{array}{l}\text { Cartazes sobre importância do } \\
\text { uso de máscara e demais } \\
\text { protocolos de prevenção }\end{array}$ \\
\hline $\begin{array}{l}\text { Monte } \\
\text { Alegre }\end{array}$ & Psicóloga & $\begin{array}{l}\text { Covid-19: Ampliando a } \\
\text { rede de suporte } \\
\text { psicossocial aos } \\
\text { profissionais de saúde }\end{array}$ & $\begin{array}{l}\text { Suporte psicossocial on line para } \\
\text { profissionais de saúde }\end{array}$ \\
\hline $\begin{array}{l}\text { Mojuí dos } \\
\text { Campos }\end{array}$ & $\begin{array}{l}\text { Educador } \\
\text { ambiental } \\
\text { Professora }\end{array}$ & Ação entre amigos & $\begin{array}{l}\text { Projeto conjunto entre dois } \\
\text { cursistas. Doação de alimentos e } \\
\text { roupas }\end{array}$ \\
\hline Itaituba & Psicóloga & $\begin{array}{l}\text { Escuta Telefônica Para } \\
\text { Usuários da UBS }\end{array}$ & $\begin{array}{l}\text { Suporte psicológico, via telefone } \\
\text { para usuários UBS }\end{array}$ \\
\hline
\end{tabular}




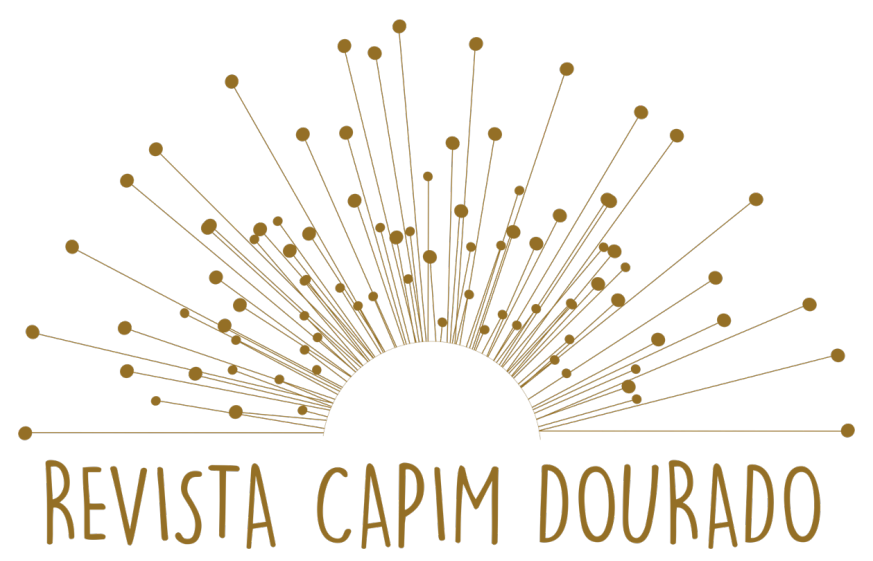

\section{Diálogos em Extensão}

ISSN n 2595-7341

Vol. 3, n. 2, Maio-Agosto, 2020

DOI: http://dx.doi.org/10.20873/uft.2595-7341.2020v3n2p70

\begin{tabular}{|c|c|c|c|}
\hline Almeirim & $\begin{array}{l}\text { Estudante de } \\
\text { farmácia }\end{array}$ & Monitoramento seguro & $\begin{array}{l}\text { Avaliação de síndrome gripal } \\
\text { para pessoas que chegam ao } \\
\text { município, após viagem }\end{array}$ \\
\hline Santarém & Psicóloga & Acolher para o bem & $\begin{array}{l}\text { Suporte psicológico, via } \\
\text { whatsapp, a jornalistas locais } \\
\text { responsáveis pela cobertura da } \\
\text { COVID-19 }\end{array}$ \\
\hline Santarém & $\begin{array}{l}\text { Terapeuta } \\
\text { ocupacional }\end{array}$ & $\begin{array}{l}\text { Rotina ocupacional } \\
\text { durante a pandemia }\end{array}$ & $\begin{array}{l}\text { Oferecer uma rotina ocupacional } \\
\text { saudável durante a quarentena e } \\
\text { informar sobre a doença }\end{array}$ \\
\hline Santarém & Enfermeira & $\begin{array}{l}\text { Informação no sistema } \\
\text { penitenciário }\end{array}$ & $\begin{array}{l}\text { Mural informativo com } \\
\text { informações principais de } \\
\text { prevenção da COVID-19 }\end{array}$ \\
\hline Santarém & Fisioterapeuta & $\begin{array}{l}\text { Plano de contingência } \\
\text { do Covid-19 para } \\
\text { serviço de atenção } \\
\text { domiciliar }\end{array}$ & $\begin{array}{l}\text { Estabelecer fluxo de ações e } \\
\text { estratégias empregadas pelo } \\
\text { Serviço de Atenção Domiciliar } \\
\text { para a COVID-19 }\end{array}$ \\
\hline Santarém & $\begin{array}{l}\text { Residente } \\
\text { psicologia }\end{array}$ & $\begin{array}{l}\text { Suporte psicológico a } \\
\text { profissionais de saúde }\end{array}$ & $\begin{array}{l}\text { Teleconsulta por vídeo chamada } \\
\text { ou telefone }\end{array}$ \\
\hline
\end{tabular}




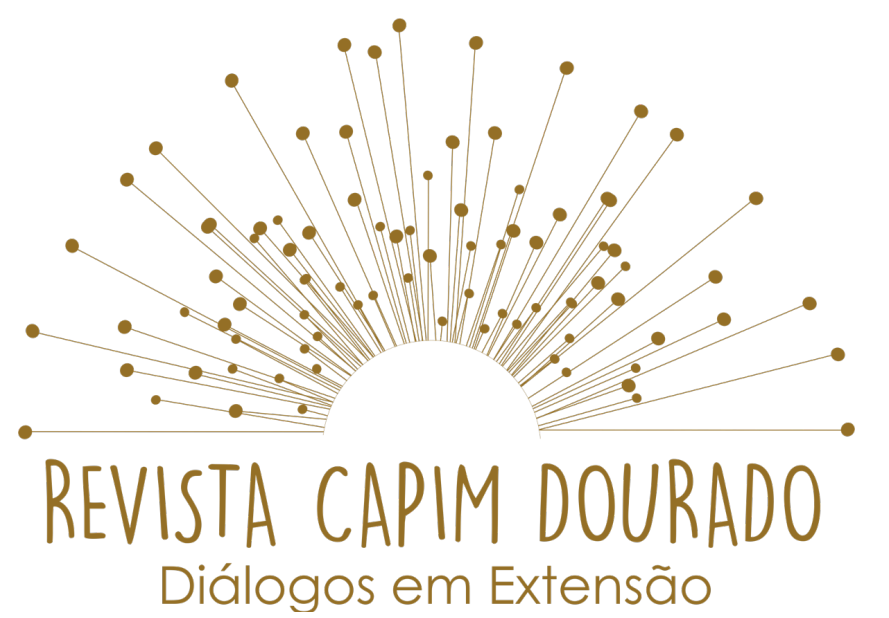

ISSN n 2595-7341 Vol. 3, n. 2, Maio-Agosto, 2020

DOI: http://dx.doi.org/10.20873/uft.2595-7341.2020v3n2p70

\begin{tabular}{l|l|l|l|} 
Santarém & $\begin{array}{l}\text { Estudante de } \\
\text { farmácia }\end{array}$ & $\begin{array}{l}\text { Saúde dos homens } \\
\text { para busca de serviços de saúde } \\
\text { e cuidados }\end{array}$ \\
\hline
\end{tabular}

Quadro 1. Exemplo de intervenções dos cursistas concluintes, Curso COVID-19 e APS, Região Oeste do Pará, 2020

Fonte: Elaboração própria

\section{Considerações finais (Dificuldades e potências)}

O curso permitiu identificar algumas dificuldades como: o acesso à internet, período de execução do curso coincidiu com a estação chuvosa da região norte, com recorrentes problemas de queda de conexão e dias sem sinal em toda a região; o desconhecimento da plataforma utilizada ou inabilidade com competências digitais por parte dos cursistas; e dificuldade dos mesmos organizarem uma rotina de estudos em casa. Essas foram agravadas pois muitos deles eram profissionais da saúde e estavam na linha de frente do combate à Covid-19, outros não concluíram o curso por estarem em recuperação da doença.

Alguns alunos justificaram que não conseguiram concluir as atividades devido às complexidades das mesmas, e da impossibilidade de atender as atividades propostas. Portanto nota-se que fazer educação em saúde na APS durante a pandemia é desafiador, principalmente à distância, sem vínculo comunitário e contato físico. 


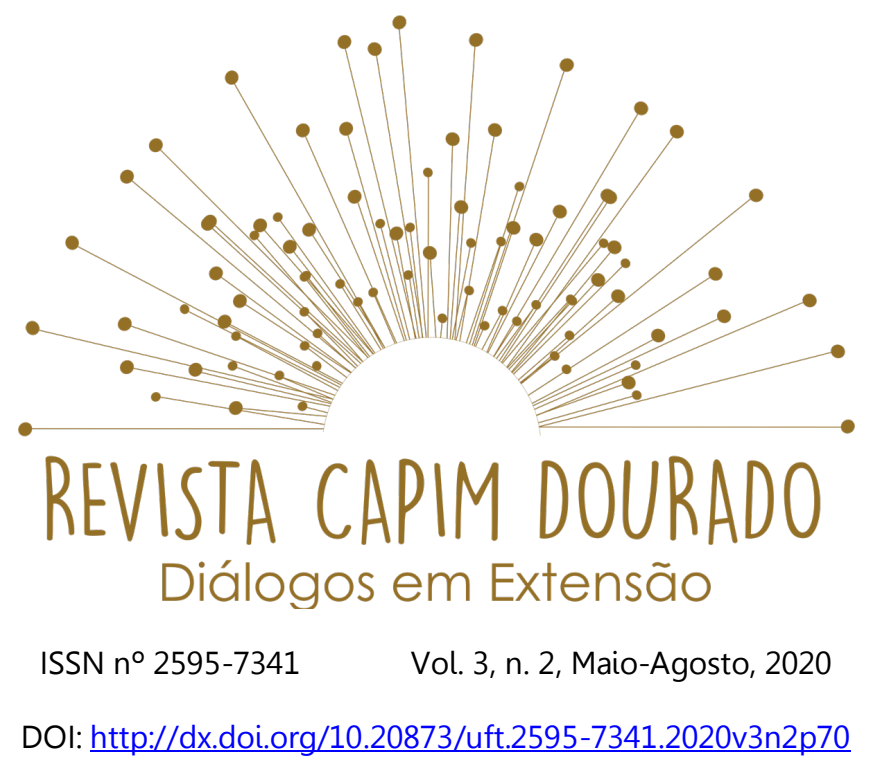

Dentre as principais potências, o curso oportunizou a criação de canais de comunicação segura entre os participantes. A utilização das tecnologias da informação possibilitou a aproximação das pessoas mesmo durante 0 distanciamento físico. Após o curso, foram criados grupos de acompanhamento dos projetos de intervenção e para qualificação e socialização de palestras on line. Criouse também um repositório de perguntas e respostas sobre as dúvidas no decorrer do curso. Por fim, consideramos como positiva a execução dos projetos que atuaram de forma interventiva e criativa na promoção de saúde nos territórios do Oeste do Pará.

\section{Referências}

CONFALONIERI, UEC. Saúde na Amazônia: um modelo conceitual para a análise de paisagens e doenças. Estud. av., São Paulo, v. 19, n. 53, p. 221-236, Apr. 2005. 